\title{
DONATO SPERDUTO, Matilde Serao e Balzac
}

\section{Marco Stupazzoni}

\section{OpenEdition \\ Journals}

\section{Edizione digitale}

URL: https://journals.openedition.org/studifrancesi/45254

DOI: 10.4000/studifrancesi.45254

ISSN: 2421-5856

\section{Editore}

Rosenberg \& Sellier

\section{Edizione cartacea}

Data di pubblicazione: 1 août 2021

Paginazione: 386

ISSN: 0039-2944

\section{Notizia bibliografica digitale}

Marco Stupazzoni, «Donato sperduto, Matilde Serao e Balzac», Studi Francesi [Online], 194 (LXV | II) | 2021, online dal 01 septembre 2021, consultato il 16 octobre 2022. URL: http://journals.openedition.org/ studifrancesi/45254 ; DOI: https://doi.org/10.4000/studifrancesi.45254

Questo documento è stato generato automaticamente il 16 octobre 2022.

\section{(c)}

Creative Commons - Attribuzione - Non commerciale - Non opere derivate 4.0 Internazionale - CC BYNC-ND 4.0

https://creativecommons.org/licenses/by-nc-nd/4.0/ 


\title{
DONATO SPERDUTO, Matilde Serao e Balzac
}

\author{
Marco Stupazzoni
}

\section{NOTIZIA}

DONATO SPERDUTO, Matilde Serao e Balzac, in M. SERAO, Storia di una monaca, a cura di D.

Sperduto, Avellino, ABE, 2019, «Sud semprevivo», pp. 11-31.

1 La profonda e sincera convinzione del magistero balzachiano è senza dubbio una tra le costanti più rilevanti e significative delle creazioni artistiche e della lezione critica proprie delle istanze veristico-naturalistiche italiane di fine Ottocento. Accanto a narratori di razza quali Giovanni Verga, Luigi Capuana e Federico de Roberto, Matilde Serao ha svolto un ruolo di primo piano nel riconoscimento dell'insegnamento impartito da Balzac e trasmesso dal romanziere francese alla cultura letteraria del nostro Paese. Allo stesso tempo, penetrando nel mondo narrativo della scrittrice italiana, è possibile cogliere, ricostruire e valorizzare un sistema di analogie e di corrispondenze, tutt'altro che generiche e marginali, con i modelli narrativi di alcuni romanzi della Comédie humaine. È il caso, ad esempio, di Storia di una monaca, racconto pubblicato inizialmente nel 1885 e, nella sua forma definitiva ed autonoma, nel 1898 .

2 Nel saggio introduttivo che precede il testo, Donato Sperduto considera le analogie e le diversità di fondo rintracciabili in Storia di una monaca e in Albert Savarus, romanzo, tra l'altro, espressamente evocato nel racconto della Serao. L'attenzione dell'A. si concentra, in particolare, sugli aspetti psicologici, colti all'interno degli ambienti e delle dinamiche collettive caratterizzanti la società contemporanea, che determinano l'esistenza e il destino delle due rispettive protagoniste: Eva Muscettola (reminiscenza della Hanska?) e Rosalie de Watteville. Eva e Rosalie, che appartengono all'aristocrazia, incarnano entrambe una condizione «di privazione quasi assoluta di amore e di comunicazione»: il loro desiderio insoddisfatto, che fa di queste due figure femminili «delle vinte» (p. 21), è il voler invano ricevere e dare amore. Tuttavia, in Storia di una 
monaca, Matilde Serao non si limita soltanto a citare l'Albert Savarus balzachiano: la scrittrice italiana, osserva l'A., riprende «il tema di madri e figlie invertendone le qualità: se in Balzac si ha a che fare con una fanciulla infame, nella Serao ad essere infame è la madre. Se il romanzo di Balzac è contro la fanciulla (Rosalie), la novella della Serao è per la fanciulla (Eva)» (p. 24). 